\title{
Factors Related to Patients' Adherence to Medication and Lifestyle Change Recommendations: Data from Canada
}

\author{
Annabel Levesque ${ }^{1}$, Han Z. Li ${ }^{2}$ \& Jasrit S. Pahal ${ }^{2}$ \\ ${ }^{1}$ Department of Psychology, Université de Saint-Boniface, Winnipeg, Canada \\ ${ }^{2}$ Department of Psychology, University of Northern British Columbia, Prince George, Canada \\ Correspondence: Annabel Levesque, Department of Psychology, Université de Saint-Boniface, 200 Avenue de la \\ Cathédrale, Winnipeg MB., R2H 0H7, Canada. Tel: 1-204-237-1818. E-mail: alevesque@ustboniface.mb.ca
}

Received: February 3, 2012

Accepted: February 17, 2012 Published: June 1, 2012

doi:10.5539/ijps.v4n2p42

URL: http://dx.doi.org/10.5539/ijps.v4n2p42

\begin{abstract}
The purpose of this study was to investigate factors related to patients' adherence to prescribed medications and recommended lifestyle changes. Two hundred and ninety-eight adults from a northern Canadian community filled out a questionnaire. Several intriguing findings emerged: (a) Adherence to lifestyle changes and participants' age presented a U-shape relationship; (b) Those who perceived themselves to be in poor health were less likely than those in good health to adhere to lifestyle changes; (c) Barriers such as the severe winter weather, lack of transportation, and cost of medications contributed negatively to adherence; and (d) If doctors provided sufficient information on the benefits and use of the prescribed medications and the proposed lifestyle changes and if patients reported trusting their doctors, they tended to adhere more. Physicians can play an important role in promoting adherence among patients. Community health workers should make efforts in reducing barriers that interfere with patient adherence.
\end{abstract}

Keywords: patient adherence, compliance, lifestyle change, medication, Canadian health care

\section{Introduction}

Despite decades of research, nonadherence to doctors' recommendations remains a major health-care issue (Lehane \& McCarthy, 2007). The adherence rate ranges between $20 \%$ and $80 \%$ depending on the population being studied, the adherence measures used, the nature of the participants' health conditions, and the characteristics of the treatment regimens (DiMatteo, 2004a; DiMatteo, Reiter \& Gambone, 1994). On average, researchers estimate that $50 \%$ of patients do not adhere to medication regimens prescribed by their doctors (Haynes, McDonald \& Garg, 2002; Sackett \& Snow, 1979) and the rate of nonadherence to lifestyle change recommendations is even higher (DiMatteo, 1994; Haynes et al., 2002; Kaplan \& Simon, 1990).

From a clinical perspective, nonadherence can reduce treatment effectiveness and lead to relapses, complications, or even death (De Geest, von Renteln-Kruse, Steeman, Degraeve \& Abraham, 1998; Cutrona et al., 2010; Lehane \& McCarthy, 2007). In addition, higher hospital admission rates resulting from nonadherence increase the cost of medical care (Bondesson, Hellström, Eriksson \& Höglund, 2009; Cutrona et al., 2010). Finally, participants failing to adhere to treatment regimens can compromise the results of clinical trials (Arbuthnott \& Sharpe, 2009; Sleator, 1985).

Overall, nonadherence represents an important and widespread issue. In order to reduce the negative impact of nonadherence, we need to understand the reasons why some patients don't follow their doctors' recommendations (De Geest et al., 1998).

\section{Literature Review}

\subsection{Factors Influencing Adherence}

Patients' adherence has long been a major concern for health-care providers (Laurier \& Lafortune, 2007; Lerner, 1997). During the 1950s, researchers started to seriously consider the issue of adherence and to study it from a scientific perspective (Trostle, 1988). Since then, many studies have been devoted to encompassing the factors predicting patients' adherence to doctors' recommendations (Conrad, 1985; Trostle, 1988; Lerner, 1997). It is estimated that over 200 variables have been linked to patients' adherence (Cameron, 1996; Lehane \& McCarthy, 2007). In order to make sense of this vast number of factors, researchers have attempted to categorize them into 
overarching dimensions, which include patients' personal characteristics, cognitive factors, and interpersonal factors. Over the last few decades, as adherence became more and more defined as a shared responsibility between patients and their physicians, an increasing body of research examined the role of the doctor-patient relationship on patients' adherence behaviours (Lehane \& McCarthy, 2007).

The first group of predictive factors considered by researchers in the 1950s were patients' personal characteristics, including socio-demographic factors and personality traits (Dunbar-Jacob, 1993). The pursuit to identifying factors predicting non-adherence within the patients reflects the prevailing attitude among health-care professionals as well as researchers at the time. Indeed, the sick role model (Parsons, 1951) stipulated that it is the patients' responsibility to do whatever possible to get well, the assumption being that patients should unconditionally comply with their doctors' recommendations (Laurier \& Lafortune, 2007). No room was left for patients to exercise autonomy or power of decision over their health (Donovan \& Blake, 1992; Laurier \& Lafortune, 2007). In fact, the use of the term "compliance" denotes an attitude that patients should obey doctors' recommendations (Conrad, 1985; Donovan \& Blake, 1992; Lerner, 1997). With this emphasis on individual responsibility, researchers who attempted to find the source of nonadherence first focused on characteristics inherent to the individual, since failure to comply was seen as the patient's fault (Donovan \& Blake, 1992; Ross, 1991; Stimson, 1974).

Researchers' attempts to find the source of nonadherence within the patients continued throughout the 1970s as social cognition models and theories were developed. Examples of social cognition models include The Health Belief Model (HBM; Rosenstock, 1974), the Theory of Reasoned Action (TRA; Ajzen \& Fishbein, 1980) or the Theory of Planned Behaviour (TPB; Ajzen, 1991), as well as the Social Learning Theory (SLT; Bandura, 1977). These models are all encompassed under the general Expectancy-Value Theory (EVT; Fishbein, 1968), which emphasizes the role of individuals' cognitions, such as attitudes, expectations, beliefs, and perceptions in guiding their behaviours. This theory is based on the premise that people decide on a course of action based on a rational decision-making process. It is assumed that people are more likely to engage in a behaviour if they perceive that a particular goal has some value and if they think the proposed action will likely lead to the valued goal (Lehane \& McCarthy, 2007; Schüz, Wurm, Ziegelmann, Warner, Tesch-Römer \& Schwarzer, 2011).

Another important element introduced by social cognition theorists is interpersonal influence (Laurier \& Lafortune, 2007; Lehane \& McCarthy, 2007). For instance, the TRA and TPB emphasize the role of peer-pressure in social behaviours. It is assumed that patients would be more likely to adhere to treatment regimens if they believe their significant others think they should do so.

Although social cognition models may yield more precise predictions of adherence, studies focusing exclusively on cognitive factors are only capturing part of the adherence phenomenon, namely, intentional adherence (Schüz et al., 2011). However, numerous studies have shown that adherence or nonadherence is not necessarily the result of a rational decision-making process (Lehane \& McCarthy, 2007). Factors contributing to unintentional adherence or nonadherence should also be investigated; these factors include treatment variables and emotional reactions to doctors' attitudes and behaviours.

In the past two decades, researchers have adopted a more critical view on the issue of adherence. Many argue that the concept of "compliance" is closely related to power relationship between doctors and patients, as expressed by the paternalistic health-care delivery model (Donovan \& Blake, 1992; Ryan, 1999; Stimson, 1974; Trostle, 1988). More recently, a new health-care paradigm has emerged; it is based on doctor-patient communication and cooperation and on the autonomy of the informed patient (Bennet, Fuertes \& Phillips, 2010; Campbell, Auerbach, \& Kiesler, 2007). This new conception comes with the new term "adherence" (Roter, Hall, Merisca, Nordstrom, Cretin, \& Svarstad, 1998). The concept of adherence contrasts with compliance in two important ways. First, it is no longer assumed that patients should unconditionally obey doctors' recommendations (Conrad, 1985). Patients have the right to exercise their autonomy when it comes to their own health (Haynes et al., 2002; Lehane \& McCarthy, 2009). Second, adherence is now defined as a shared responsibility between doctors and their patients (Bennet et al., 2010; Roter et al., 1998). Indeed, the concept of adherence emphasizes the role doctors and patients play in promoting patients' adherence (Laurier \& Lafortune, 2007). Therefore, many researchers now seek to find the source of nonadherence within the doctor-patient relationship.

\subsection{Empirical Evidences}

\subsubsection{Personal Characteristics}

Research on how patients' socio-demographic and personality characteristics influence adherence remains controversial (DiMatteo, 1994; Kaplan \& Simon 1990). In a review of the adherence literature, it was found that 
the only demographic characteristic consistently associated with adherence was age (Karamanidou, Clatworthy, Weinman \& Horne, 2008) but the direction of the relationship is unclear. Age has been found to be positively related to adherence in certain studies (e.g., Horne \& Weinman, 1999; Sherbourne, Hays, Ordway, DiMatteo \& Kravitz, 1992) and negatively related to adherence in others (e.g., Aggarwal \& Mosca, 2010; Jerant, Chapman, Duberstein, Robbins \& Franks, 2010). Mixed results are also found in studies that examined the influence of personality traits on adherence. In their review, Karamanidou et al. (2008) found that four out of eight studies investigating the relationship between personality and adherence obtained significant results, while the other four studies reported no effects. Another group of researchers found that of the five-factor personality model, only neuroticism was significantly related to nonadherence (Jerant et al., 2010). It seems examining personal characteristics is not an effective approach to the prediction of patients' adherence, the reason being that this approach fails to recognize situational factors and individual differences when responding to doctors' recommendations (Kaplan \& Simon, 1990). This phenomenon is well explained by Rosenstock's famous saying: There are no chronic nonadherent patients (Rosenstock, 1988).

\subsubsection{Cognitive Factors}

A vast body of research has studied how cognitive processes predict adherence behaviours. It appears that cognitive factors are better predictors of adherence than personal characteristics (Mann, Ponieman, Leventhal, \& Halm, 2009). It has been shown that patients who believe that the treatment can have some benefits (Foster, Smith, Bosnic-Anticevich, Usherwood, Sawyer, Rand, \& Reddel, 2011; Horne \& Weinman, 1999), a disease can have serious consequences (DiMatteo, Haskard \& Williams, 2007; Stafford, Jackson \& Berk, 2008), they are susceptible to a disease (Becker, 1977), they have the ability to carry out the prescribed treatment regimen (Brus, van de Laar, Taal, Rasker \& Wiegman, 1999; Dilorio et al., 2009), and those who have a positive attitude toward the treatment (Miller, Wikoff, Hiatt, 1992) and have more knowledge about diseases or health in general (Gellad, Grenard, \& Marcum, 2011) adhere more to doctors' prescribed treatment regimens.

Conversely, perceived barriers (Gellad et al., 2011; Horne \& Weinman, 1999), side-effects (Foster et al., 2011; Gellad et al., 2011; Mann et al., 2009), and perceived health status (Sherbourne et al., 1992) appear to be negatively related to adherence. DiMatteo and her colleagues (2007) also found that poor health is related to nonadherence, but only for patients who face serious health conditions. Despite these evidences, other studies reported no relationship between cognitive factors and adherence (Lehane \& McCarthy, 2007). For instance, Brus et al. (1999) observed that perceived barriers, outcome expectations, perceived attitudes, and health status did not predict adherence behaviours.

\subsubsection{Interpersonal Factors}

One aspect of participants' interpersonal relationships that appears to have a consistent influence on adherence is social support (Karamanidou et al., 2008; Molloy, Perkins-Porras, Bhattacharyya, Strike \& Steptoe, 2008). Sherbourne et al. (1992) found that the quality of interpersonal relationships is more important than the quantity of relationships in predicting adherence. DiMatteo (2004b) reported that family conflicts are related to poor adherence.

A few researchers examined the impact of peer-pressure on medical adherence. Miller et al. (1992) found that peer-pressure predicts patients' intention to adhere to prescribed treatments, which in turn influences adherence to lifestyle changes. The use of pressure and persuasion strategies by spouses has also been linked to greater adherence (Stephens, Fekete, Franks, Rook, Druley \& Greene, 2009). However, another group of researchers reported that when friends and family members have strong opinions about asthma patients' medication use, patients were less likely to take their medications (Foster et al., 2011). Brus et al. (1999) found no relationship between social support, peer-pressure, and adherence.

\subsubsection{Doctor-patient Relationship}

Many aspects of the doctor-patient relationship have been studied in relation to patients' adherence. In general, results indicate that the quality of the communication and the relationship between doctors and patients is positively related to patients' adherence (e.g., Bennet et al., 2010; Burgoon, Parrott, Burgoon, Coker, Pfau, \& Birk, 1990; Burgoon, Pfau, Parrott, Birk, Coker \& Burgoon, 1987; DiMatteo et al., 1993; Gellad et al., 2011; Ryan, 1999). For instance, it has been shown that information provided to patients by their doctors is positively related to adherence (DiMatteo et al., 1994; Falvo, Woehlke, \& Deichman, 1980; Gellad et al., 2011). Involving patients in the decision-making process (Arbuthnott \& Sharpe, 2009; Bultman \& Svarstad, 2000), providing support (Carpenter, DeVellis, Fisher, DeVellis, Hogan \& Jordan, 2010; Siegel, Turner \& Haselkorn, 2008), and showing concern for patients (Falvo et al., 1980) also seem to enhance patients' adherence. Moreover, patients who have more trust in their physicians were more likely to follow their recommendations (Bennet et al., 2010; 
Kerse, Buetow, Mainous, Young, Coster \& Arroll, 2004). Concordance between physicians' and patients' views on the disease, the treatment plan, and the role patients should play in their own health appears to enhance patients' adherence (Bennet et al., 2010; Cvengros, Christensen, Hillis \&Rosenthal, 2007; Kerse et al., 2004). However, other researchers found no relationship between the doctor-patient relationship and patients' adherence (Campbell et al., 2007; Kerse et al., 2004).

\subsection{Limitations of Previous Research}

There are certain limitations related to many of the studies reported in the literature and some aspects have not been fully investigated. First, adherence has been seldom researched in Canada. Since the Canadian health-care system operates in a unique way, research on adherence can yield different results compared to previous studies reported in the literature. For instance, Kennedy and Morgan (2009) found that Canadians were less likely to report cost-related nonadherence compared to Americans. Moreover, general practitioners who provide nonemergency care in Canada are paid on a fee-to-service system. As a result, general practitioners tend to limit the consultation time to less than 15 minutes (Li, Desroches, Yum, Koehn \& Deagle, 2007). This system may prevent general practitioners from discussing issues related to adherence with patients. Second, most of the studies reported in the literature sought for the presence of linear relationships. A possible explanation for the contradictory results found in previous studies is that adherence may entertain curvilinear relationships with some factors. This study attempted to overcome a dearth in the scientific literature on adherence and to address the following questions:

1) How often do patients adhere to prescribed medications?

2) How often do patients adhere to recommended lifestyle changes?

3) What is the nature of the relationship (linear or curvilinear) that links adherence to other determining factors?

4) What are the important factors in predicting adherence?

\subsection{Objectives}

The objectives of this study were (a) to evaluate whether demographic factors, cognitive factors, peer influence, and factors pertaining to the doctor-patient relationship are related to patients' adherence to doctors' recommendations with regard to medications and lifestyle changes; (b) to determine the relative strength of these variables in relation to adherence; and (c) to explore the nature of the relationships. To address these objectives, a correlational design was used in the study.

\section{Methods}

\subsection{Participants}

A total of 298 people completed the questionnaire that was developed for this study. However, two participants were excluded from data analyses since more than $25 \%$ of the questions were left unanswered. The remaining 296 participants ranged in age from 18 to 74 years, with a mean age of 36 years $(S D=13.89)$. The sample was comprised of 160 women (54\%) and 136 men (46\%).

\subsection{Procedure}

Approval to conduct this study was granted by a university ethics committee board. The study was conducted in a town with a population of about 75000 located in Northern British Columbia, Canada. Participants were recruited in shopping malls and local food markets using a convenience sampling strategy. They were approached by two research assistants who asked them whether they would like to take part in the study. To be eligible to take part in this study, participants were asked whether they had a regular family doctor and whether they had seen their doctor at least once in the previous six months for nonemergency complaints. After participants gave their informed consent in writing, they were asked to complete a questionnaire at the place of recruitment, which took approximately 20 minutes. Participants did not receive any payment for their participation. Data collection was completed within one year.

\subsection{Measures}

\subsubsection{Adherence}

Most of the questions in the questionnaire were adapted from previous research. The adherence questions were from Pahal (2004), which asked about adherence to medications and lifestyle changes separately. Adherence to medications was measured using a single item that measured past adherence behaviours with regard to medication taking (How often do you follow the doctors' instructions regarding taking medications?). Adherence to lifestyle changes was also assessed on a single item (How often do you follow the doctor's instructions 
regarding lifestyle changes?). Respondents indicated their adherence to medications and to lifestyle changes using a 5 -point scale $(1=$ never and $5=$ always $)$.

\subsubsection{Doctor-patient Relationship}

The doctor-patient relationship questions were adapted from Roter et al. (1997), validated by Li et al. (2007). Three variables pertaining to the doctor-patient relationship were included: doctors' friendliness when making decisions about medication-taking and lifestyle changes, the degree of information provided by family doctors regarding medication-taking and lifestyle changes, as well as trust in family doctors. Four items assessed the importance respondents placed on doctors' friendliness. A mean score was computed $(\alpha=.84)$ with possible scores ranging from one to five. Higher scores indicated that respondents believed family doctors should show a friendly attitude when asking to take medications or to change their lifestyle. Patients were asked whether their doctors provided enough information on medication regimens and recommended lifestyle change. This variable was measured with three items on a 5-point scale. A mean score ranging from one to five was computed $(\alpha=.82)$ with high scores indicating that family doctors provided enough information on how to take medications and to change their lifestyle and reasons why they should follow these recommendations. Finally, participants were asked whether they trust their doctors' recommendations to take medications or to change their lifestyle using three items. A mean score was computed $(\alpha=.55)$ which yielded scores that ranged from one to five with higher scores indicating that respondents trust their family doctors.

\subsubsection{Cognitive Factors}

Questions regarding cognitive factors were adapted from Verde and Li (2003), which included respondents' perceptions of their current health status, their general attitude towards medications, their beliefs about the importance of adhering to medications and lifestyle changes when facing serious health problems, and the perceived barriers that prevent medication and lifestyle change adherence. Current health status was assessed with one item measured on a 4-point scale $(1=$ excellent, $2=\operatorname{good}, 3=$ fair, and $4=$ poor $)$. Attitude towards medications was assessed using a single item measured on a 5-point scale where a higher score indicated a more positive attitude towards medications. Seriousness of disease was also measured on a 5-point scale where a higher score indicated a stronger inclination to take medications or to change their lifestyle when facing a serious illness. Perceived barriers were measured with 10 items: five items assessed the impact of costs, two items addressed the issue of lack of transportation, and three items assessed whether the severe winter weather had an impact on their decision to take medications and to change their lifestyle. All the items assessing barriers were measured on a 5 -point scale and a mean score was computed $(\alpha=.76)$ ranging from one to five, where a higher score indicated that respondents perceived more barriers.

\subsubsection{Peer Influence}

Two items measured on a 5-point scale assessed the degree to which friends and family members influence the respondents' decisions to take medications and to change their lifestyle. Two additional items assessed the influence of partners. These items were adapted from Li and Browne (2000). Based on these four items a mean score that ranged from one to five was computed $(\alpha=.67)$. A high score indicated that peers represent an important source of influence for the respondent when deciding to take medications and change their lifestyle.

\subsubsection{Demographic Factors}

The demographic questions were from Li and Browne (2000), which assessed respondents' age, gender, level of education, annual income, and language. Level of education was obtained by asking respondents to indicate, on a 5 -choice scale, the highest level of education they have completed. Possible answers were none, some grade school (but did not complete grade 12), high school (grade 12), certificate or diploma from college, and university degree. Annual household income was measured using five income brackets: $\$ 10000$ or less; \$10 001 to $\$ 25000 ; \$ 25001$ to $\$ 40000 ; \$ 40001$ to $\$ 55000$; and $\$ 55001$ or more. Respondents were also asked whether English was their first language. If English was not their first language, they were asked about their English language fluency $(1=$ fluent, $2=$ fair , and $3=$ poor $)$.

\subsection{Statistical Analysis}

Prior to conducting the analyses, the data were examined for univariate and multivariate normality, linearity, homoscedasticity, absence of outliers, and absence of multicolinearity. Three outliers were found; these data were not included in the analyses. Data analyses were performed with the remaining 293 participants. Medication adherence was negatively skewed and was therefore transformed using a logarithm transformation method.

A series of $t$ tests were conducted to verify whether men and women differed with respect to the adherence 
variables and the predictors used in the main analyses. No significant differences were observed between the gender groups $(p>.05)$. Therefore, the analyses were performed with the whole sample.

Correlation analyses were conducted in order to evaluate the relationship between adherence to medications and lifestyle changes and the four categories of predictors. Hierarchical regression analyses were then performed in order to determine the relative importance of the four categories of predictors. Demographic variables were entered at step one followed by the cognitive factors. Peer influence was introduced next and the variables pertaining to the doctor-patient relationship were entered at step four. A fifth step was introduced to the models in order to explore possible curvilinear relationships between the predictors and the two adherence variables. In order to verify for curvilinear effects, the predictors were transformed to their quadratic function $\left(\mathrm{X}_{i}^{2}\right)$. However, prior to transforming the variables, they were centered, which was done by subtracting the mean of the variable to its individual scores, so that each variable had a mean of zero (Note 1). The analyses were performed twice, once with adherence to medications as the predicted variable and once with adherence to lifestyle changes.

\section{Results}

Descriptive analyses conducted on demographic variables revealed that the majority of the respondents reported English as their first language, whereas $7 \%$ of the sample reported that English was not their first language. However, they all rated their English as either fluent or fair. Ten percent of the respondents attended public school but did not finish grade twelve, 27\% obtained their high school diploma, 37\% had a college diploma or certificate, and $26 \%$ had a university degree. The majority of the people who took part in this study were employed, while $8 \%$ were students, $1 \%$ were retired, and $17 \%$ were unemployed. Twelve percent of the participants had an annual household income below $\$ 10000 ; 17 \%$ had an annual income between $\$ 10001$ and $\$ 25000 ; 16 \%$ between $\$ 25001$ and $\$ 40000 ; 9 \%$ between $\$ 40001$ and $\$ 55000$; and $46 \%$ reported having an annual income of more than $\$ 55000$. The majority of the respondents rated their current health status as good, $19 \%$ as excellent, $17 \%$ as fair, and $3 \%$ as poor. Mean scores and standard deviations for the other predictors and for the adherence variables are reported in Table 1.

Table 1. Means (standard deviations) and Pearson correlations among adherence and predictive variables

\begin{tabular}{|c|c|c|c|c|c|c|c|c|c|c|c|c|c|c|c|c|}
\hline & $M(S D)$ & 1 & 2 & 3 & 4 & 5 & 6 & 7 & 8 & 9 & 10 & 11 & 12 & 13 & 14 & 15 \\
\hline \multicolumn{17}{|l|}{ DEMOGRAPHIC FACTORS } \\
\hline 1. Age & & - & -.09 & .08 & $.30^{* *}$ & -.01 & .08 & -.09 & -.10 & -.08 & $-.15^{* *}$ & .05 & $.16^{* *}$ & $.13^{*}$ & $.19^{* * *}$ & .05 \\
\hline 2. Education & & & - & .02 & $.17^{* *}$ & .08 & $-.22^{* *}$ & -.09 & .04 & -.09 & -.03 & -.01 & $-.15^{* *}$ & -.05 & .05 & .00 \\
\hline 3. Language & & & & - & -.04 & -.11 & -.08 & .06 & .09 & .05 & .02 & .03 & -.05 & -.09 & -.02 & $.12^{*}$ \\
\hline 4. Income & & & & & - & -.09 & $-.14^{*}$ & -.06 & .03 & $-.29^{* *}$ & -.08 & -.07 & .01 & .07 & $.16^{* *}$ & .01 \\
\hline 5. Gender & & & & & & - & .03 & -.02 & -.10 & .01 & .01 & .06 & .00 & .05 & .09 & .07 \\
\hline \multicolumn{17}{|l|}{ COGNITIVE FACTORS } \\
\hline 6. Current Health & $2.04(0.70)$ & & & & & & - & .05 & -.09 & $.26^{* *}$ & .02 & .06 & -.01 & -.07 & -.07 & $-.22^{* * *}$ \\
\hline 7. Attitude Towards Medications & $2.25(1.13)$ & & & & & & & - & -.11 & -.03 & .02 & -.05 & .06 & $.22^{* *}$ & $.12^{*}$ & .05 \\
\hline 8. Seriousness of Diseases & $3.49(1.07)$ & & & & & & & & - & .10 & .11 & .07 & $-.18^{* *}$ & $-.14^{*}$ & -.08 & $-.12^{*}$ \\
\hline 9. Barriers & $2.28(0.64)$ & & & & & & & & & - & $.35^{* *}$ & $.41^{* *}$ & $-.12^{*}$ & $-.36^{* *}$ & $-.34^{* * *}$ & $-.17^{* *}$ \\
\hline 10. PEER INFLUENCE & $2.60(0.87)$ & & & & & & & & & & - & $.33^{* *}$ & -.10 & $-.28^{* *}$ & $-.22^{* * *}$ & -.07 \\
\hline \multicolumn{17}{|l|}{ DOCTOR-PATIENT RELATION } \\
\hline 11. Friendliness & $3.10(0.93)$ & & & & & & & & & & & - & .03 & $-.26^{* *}$ & $-.13^{*}$ & -.08 \\
\hline 12. Information & $3.87(0.78)$ & & & & & & & & & & & & - & $.45^{* *}$ & $.32^{* * *}$ & $.16^{* *}$ \\
\hline 13. Trust & $3.46(0.79)$ & & & & & & & & & & & & & - & $.38^{* * *}$ & $.19^{* * *}$ \\
\hline \multicolumn{17}{|l|}{ ADHERENCE } \\
\hline 14. Adherence to Medications & $4.44(0.69)$ & & & & & & & & & & & & & & - & $.20^{* * *}$ \\
\hline $\begin{array}{l}\text { 15. Adherence to Lifestyle } \\
\text { Changes }\end{array}$ & $3.39(0.87)$ & & & & & & & & & & & & & & & - \\
\hline
\end{tabular}


Pearson product-moment correlation coefficients are also displayed in Table 1. Using a Sidak correction for multiple correlations, it appeared that older respondents adhered more to their medication regimens compared to younger respondents. Those who rated their health as being good or excellent adhered more to doctors' recommendations to change their lifestyle. Respondents who reported facing more barriers were less likely to adhere to their medication regimens. The influence of peers was also negatively related to adherence to medications. Furthermore, two variables pertaining to the doctor-patient relationship were significantly related to adherence to medications or to lifestyle changes - information and trust.

The results reported in Table 2 revealed that the regression model explained $28 \%$ of the variance in respondents' medication adherence. More specifically, respondents' age was positively related to medication adherence. Beyond the variance explained by the demographic variables, respondents' perception of barriers was negatively related to medication adherence, while a positive attitude towards medications in general was positively related to medication adherence. Peer influence did not add any information in explaining respondents' adherence to medications. However, two variables pertaining to the doctor-patient relationship added variance to the model in addition to the demographic and cognitive factors, namely information given by family doctors and trust in doctors. No curvilinear relationships were observed.

Table 2. Regression coefficients for predictors of respondents' adherence to medications

\begin{tabular}{|c|c|c|c|c|c|}
\hline Variables & $R^{2}$ & $\Delta R^{2}$ & $b$ & $\mathrm{~B}$ & $95 \% \mathrm{CI}$ \\
\hline Step 1 & $.06^{*}$ & & & & \\
\hline Age & & & $0.01 * *$ & 0.16 & $0.00,0.00$ \\
\hline Education & & & 0.01 & 0.04 & $-0.02,0.03$ \\
\hline Language & & & -0.01 & -0.02 & $-0.09,0.07$ \\
\hline Income & & & 0.01 & 0.11 & $0.00,0.03$ \\
\hline Gender & & & 0.03 & 0.10 & $-0.01,0.07$ \\
\hline Step 2 & $.17^{* *}$ & $.11^{* *}$ & & & \\
\hline Current Health & & & 0.00 & 0.00 & $-0.03,0.03$ \\
\hline Attitude Towards Medications & & & $0.02 *$ & 0.14 & $0.00,0.04$ \\
\hline Seriousness of Diseases & & & 0.00 & -0.01 & $-0.02,0.02$ \\
\hline Barriers & & & $-0.09 * *$ & -0.32 & $-0.12,-0.06$ \\
\hline Step 3 & $.18^{* *}$ & .01 & & & \\
\hline Peer Influence & & & -0.02 & -0.10 & $-0.04,0.00$ \\
\hline Step 4 & $.26^{* *}$ & $.08^{* *}$ & & & \\
\hline Friendliness & & & 0.00 & 0.01 & $-0.02,0.02$ \\
\hline Information & & & $0.05 * *$ & 0.21 & $0.02,0.07$ \\
\hline Trust & & & $0.04 *$ & 0.16 & $0.01,0.07$ \\
\hline Step 5 & $.28^{* *}$ & .02 & & & \\
\hline
\end{tabular}

$* \mathrm{p}<.05, * * \mathrm{p}<.01$.

The results reported in Table 3 revealed that $19 \%$ of the variability in lifestyle adherence was explained by the four groups of predictive variables. Respondents who reported that English was not their first language appeared to adhere more to lifestyle change recommendations. Cognitive factors explained variability in lifestyle adherence beyond what was explained by demographic factors. More specifically, respondents who rated their health as poor, those who faced serious illness, and those who reported facing barriers were less likely to adhere to doctors' recommendations to change their lifestyle. Peer influence as well as doctor-patient relationship did not add any new information in explaining respondents' adherence to lifestyle changes. However, participants' age appeared to entertain a U-shaped relationship with adherence to lifestyle changes. This curvilinear relationship is presented in Figure 1. 
Table 3. Regression coefficient for predictors of respondents' adherence to lifestyle changes

\begin{tabular}{|c|c|c|c|c|c|}
\hline Variables & R2 & $\Delta \mathrm{R} 2$ & $\mathrm{~b}$ & B & $95 \% \mathrm{CI}$ \\
\hline Step 1 & .02 & & & & \\
\hline Age & & & 0.00 & 0.04 & $-0.01,0.01$ \\
\hline Education & & & 0.00 & -0.01 & $-0.11,0.11$ \\
\hline Language & & & $0.45^{*}$ & 0.13 & $0.04,0.85$ \\
\hline Income & & & 0.01 & 0.02 & $-0.06,0.08$ \\
\hline Gender & & & 0.15 & 0.09 & $-0.05,0.36$ \\
\hline Step 2 & $.11^{* *}$ & $.09^{* *}$ & & & \\
\hline Current Health & & & $-0.27 * *$ & -0.22 & $-0.42,-0.12$ \\
\hline Attitude Towards Medications & & & 0.03 & 0.04 & $-0.06,0.12$ \\
\hline Seriousness of Diseases & & & $-0.10^{*}$ & -0.12 & $-0.19,0.00$ \\
\hline Barriers & & & $-0.17 *$ & -0.12 & $-0.33,0.00$ \\
\hline Step 3 & $.11^{* *}$ & .00 & & & \\
\hline Peer Influence & & & -0.01 & -0.01 & $-0.13,0.11$ \\
\hline Step 4 & $.13^{* *}$ & .02 & & & \\
\hline Friendliness & & & -0.03 & -0.03 & $-0.15,0.09$ \\
\hline Information & & & 0.09 & 0.09 & $-0.05,0.24$ \\
\hline Trust & & & 0.10 & 0.09 & $-0.06,0.26$ \\
\hline Step 5 & $.19^{* *}$ & $.06^{*}$ & & & \\
\hline Age & & & $0.01 * *$ & 0.25 & $0.00,0.00$ \\
\hline
\end{tabular}

$* \mathrm{p}<.05, * * \mathrm{p}<.01$.

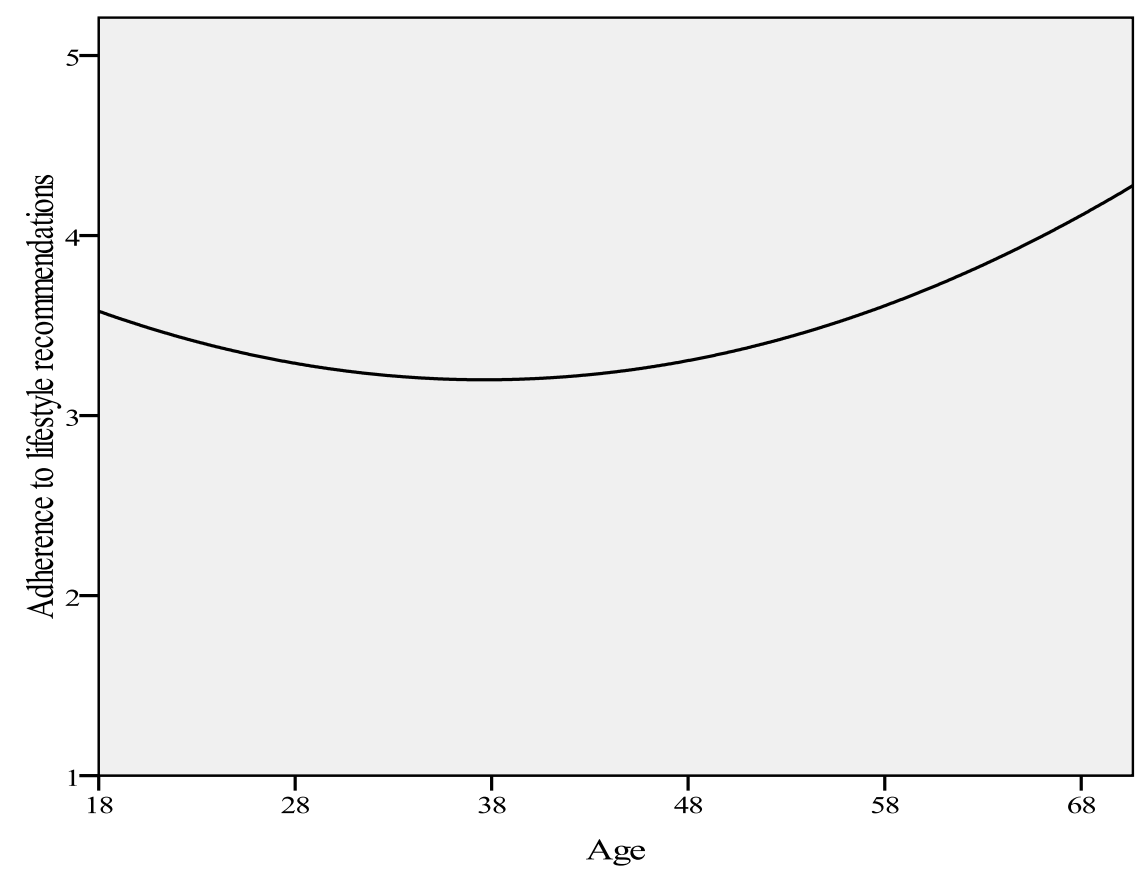

Figure 1. Relationship between respondents' age and adherence to lifestyle change recommendations 


\section{Discussion}

\subsection{Principal Findings}

A significant relationship was found between participants' age and adherence to medication and lifestyle change recommendations. Older participants were more likely to report adhering to their medication regimens in comparison with younger respondents. One intriguing finding is that adherence to lifestyle changes and respondents' age seem to entertain a U-shaped relationship, with younger and older respondents being more likely to adhere to lifestyle change recommendations compared to those in between. However, the increase in adherence was more accentuated for older respondents, whereas younger respondents were only slightly more likely to adhere to lifestyle changes compared to those in their 30s and 40s. It is possible that older participants adhere more to their doctors' recommendations to change their lifestyle because they see themselves as more vulnerable to illness (Karamanidou et al., 2008). The curvilinear relationship found between age and adherence to lifestyle changes may in part explain why previous studies reported contradictory results with respect to the effect of age on patients' adherence behaviours.

The correlation coefficients between adherence and other demographic factors were not significant when using a Sidak correction for multiple correlations. These results support the observation reported by other researchers that static characteristics inherent to individuals are not very good indicators of adherence compared to other situational factors or individual factors that can be altered (DiMatteo, 2004a; Kaplan \& Simon 1990). This finding indicates that adherence can indeed be promoted. Three promising avenues for promoting adherence reside within the patients' cognitive processes, the influence of peers, and the doctor-patient relationship.

With respect to cognitive factors, the results of the regression analyses indicate that all four cognitive variables were significantly related to adherence to medications or lifestyle changes. Perceived barriers appeared to be most strongly related to adherence. From the perspective of health-care policy makers and community health workers, this finding points to the importance of helping patients reduce barriers. One group of people who seem to be at greater risk are those in the lower income brackets. Our analysis indicates that respondents with lower annual household income faced more barriers, which in turn can affect adherence to medications and lifestyle changes.

In addition to perceived barriers, respondents who reported having a positive attitude towards medications in general were more likely to adhere to their medication regimens compared to those with a negative attitude. Participants who perceived themselves to be in poor health and those who believed in the importance of adhering to their doctors' recommendations only when facing a serious illness seemed to adhere less to lifestyle change recommendations. A negative relationship between current health and adherence has been observed elsewhere (DiMatteo et al., 2007; Sherbourne et al., 1992). Sherbourne and her colleagues (1992) hypothesized that patients who are in poor health might adhere less because they may feel frustrated and hopeless and they may come to believe that their behaviours have no effect on their health. As previous studies have shown, patients who believe in the benefits of their treatment and who believe that their behaviours can have positive outcomes tend to adhere more to doctors' recommendations (Becker, 1977, DiMatteo, 1994; DiMatteo et al., 1994; Horne \& Weinman, 1999).

The results of this study indicate that respondents who reported taking into consideration the views of family members and friends when deciding whether to take medications were generally less likely to follow their medication regimens. This result may be explained by the negative correlation found between peer influence and trust in one's doctor. Indeed, those who tend to take into consideration the views of their peers were also the ones who reported not trusting their doctors, which in turn was related to low adherence. For these patients, involving family members and close friends when planning a treatment regimen may have a positive influence on their adherence behaviours.

Two variables pertaining to the doctor-patient relationship have been found to be related to adherence-provision of information and trust-evidencing that doctors can play an important role in promoting adherence in their patients. The findings suggest that doctors should provide sufficient information to their patients regarding the reasons why they should adhere to their prescribed regimen and make sure they understand how to properly follow the treatment regimen. The positive influence of information on medication adherence appears critical given that a recent study showed that about $50 \%$ of patients reported receiving conflicting medication information from health professionals, which in turn, negatively affected adherence (Carpenter et al., 2010). In addition, the results of the present study suggest that doctors should strive to promote a sense of trust in their patients, as patients who trust their doctors were more likely to adhere to their doctors' recommendations. 


\subsection{Limitations}

The results of this study show that adherence is related to many factors. However, because of the nature of correlational and cross-sectional research designs, it is difficult to assert from these results whether these factors influenced adherence or if, on the contrary, adherence influenced some of these factors. For some variables, such as age, which cannot be manipulated, the direction of the relationship can be more easily implied. Age is probably a determinant of adherence. However, that does not mean that age necessarily has a direct impact on adherence. In fact, other factors can possibly mediate the relationship between age and adherence. For instance, it is possible that greater adherence to medication and lifestyle recommendations among older respondents may be explained by age being positively related to trust in doctors and information provided by doctors. Older respondents in this study reported trusting their doctors and receiving more information from their doctors in comparison with younger respondents, which, in turn, seemed to promote adherence.

The use of a convenient sample can also limit the generalization of the research findings. Those who took part in this study may present certain characteristics that distinguish them from the rest of the population. For instance, they may be more inclined to adhere to their doctors' recommendations. Another limitation is related to the use of a retrospective self-reported measure of adherence, which could have resulted in distorted estimations of adherence behaviours due to social desirability. It has been shown that participants tend to overestimate the extent to which they adhere to doctors' recommendations (Haynes, Taylor, Sackett, Gibson, Bernholtz \& Mukherjee, 1980).

Finally, the trust measure had a relatively low reliability coefficient. As a result, research findings may be less robust, especially with respect to the analyses testing for curvilinear relationships. By elevating participants' scores to the power of two, not only were the real scores multiplied but also the measurement error. In turn, elevated measurement error could have reduced the statistical power of the analyses.

\subsection{Implications and Future Research}

The findings reported in this paper have noteworthy implications for researchers. The results point to the importance of examining for more complex relationships. One explanation for the contradictory results reported in the literature on adherence is that adherence may entertain curvilinear relationships with other variables.

The findings of this study also demonstrate that it is important to consider adherence to medications and adherence to lifestyle changes separately. First, although these two types of adherence were significantly related to one another, the correlation coefficient was far from being large enough to suggest that these variables were in fact measuring the same construct. Second, with the exception of perceived barriers, information, and trust, the factors that were found to be linked to adherence to medications were not the same ones that were linked to adherence to lifestyle changes. In other words, it seems that the reasons why patients adhere or do not adhere to pharmacotherapy are not the same reasons that explain lifestyle change adherence. Therefore, interventions aiming at promoting adherence should be tailored specifically to address the type of treatment regimens prescribed to patients.

Another strength of this study lies in adherence being measured on a continuum. Past studies have measured adherence on a dichotomous variable, classifying people as either adherent or non-adherent, which presents the problem of having to identify an arbitrary cut-off score. At what point a person is considered non-adherent is subject to debate. Measuring adherence on a continuum allows for a conceptualization of adherence as a relative concept. Indeed, actual adherence scores have no intrinsic meaning in themselves. Only the relative distance between the respondents' scores is meaningful. Thus, people can be seen as more or less adherent compared to other individuals or to another point in time.

In future studies, researchers should assess for moderating and mediating effects in order to unravel the mechanisms involved in the process that leads to adherence. It is also important to keep in mind that our effort to understand the factors leading to non-adherence should be aimed at reducing the negative consequences of non-adherence and not necessarily at reducing non-adherence per se. In fact, if non-adherence is the result of a rational decision-making process where the patient has a good understanding of his health condition and of the dangers of not following doctors' recommendations, non-adherence may be the best available option from the patient's perspective. Therefore, in future studies, there is a need to consider not only the adherence behaviours of patients, but also the underlying attitudes leading to adherence or non-adherence. It would be important to distinguish between patients who do not adhere based on a conscious and rational decision-making process where they are actively involved in their health care, versus patients who make an irrational or uninformed decision not to adhere. The objective should not necessarily be to have patients always adhere to doctors' orders, but to make them active, informed, and rational decision makers. 
In summary, our research has made four contributions to the field. First, we found a U-shape relationship between age and adherence to recommended lifestyle changes, which had not been reported in past research. Second, contrary to common sense, those who perceived themselves to be in poor health were less likely than those in good health to adhere to lifestyle changes. Future efforts to promote adherence should pay more attention to patients in poorer health to find out both the reasons why they are less likely to adhere and the strategies to improve adherence. Third, barriers such as the severe winter weather, lack of transportation, and the high cost of medications contributed negatively to adherence. Barriers, especially the northern-specific barriers should have profound implications for community workers. To help northerners to adhere more to recommended lifestyle changes, unique tactics addressing these barriers need to be in place. Finally, our finding confirms the notion that doctors' efforts matter a great deal in promoting adherence. Patients are more likely to adhere to doctors' advice if doctors provide sufficient information on how to use the prescribed medications and on the benefits of adherence, because doctors' efforts help to build trust in their patients.

\section{References}

Aggarwal, B., \& Mosca, L. (2010). Lifestyle and psychosocial risk factors predict non-adherence to medication. Annals of Behavioral Medicine, 40, 228-233. http://dx.doi.org/10.1007/s12160-010-9212-6

Ajzen, I. (1991). The theory of the planned behaviour. Organisational Behaviour and Human Decision Processes, 50, 179-211. http://dx.doi.org/10.1016/0749-5978(91)90020-T

Ajzen, I., \& Fishbein, M. (1980). Understanding attitudes and predicting social behaviour. Englewood Cliffs, NJ: Prentice-Hall.

Arbuthnott, A., \& Sharpe, D. (2009). The effect of physician-patient collaboration on patient adherence in non-psychiatric medicine. Patient Education and Counselling, 77, 60-67. http://dx.doi.org/10.1016/j.pec.2009.03.022

Bandura, A. (1977). Social learning theory. New York, NY: General Learning Press.

Bennet, J. K., Fuertes, J. N., \& Phillips, R. (2010). The role of patient attachment and working alliance on patient adherence, satisfaction, and health-related quality of life in lupus treatment. Patient Education and Counseling, 85, 53-59. http://dx.doi.org/10.1016/j.pec.2010.08.005

Becker, M. H. (1977). The Health Belief Model and prediction of dietary compliance: A field experiment. Journal of Health and Social Behavior, 18, 348-366. http://dx.doi.org/10.2307/2955344

Bondesson, A., Hellström, L., Eriksson, T., \& Höglund, P. (2009). A structured questionnaire to assess patient compliance and beliefs about medicines taking into account the ordered categorical structure of data. $\begin{array}{llllll}\text { Journal of Evaluation in Clinical Practice, } & 15,723 .\end{array}$ http://dx.doi.org/10.1111/j.1365-2753.2008.01088.x

Brus, H., Van de Laar, M., Taal, E., Rasker, J., \& Wiegman, O. (1999). Determinants of compliance with medication in patients with rheumatoid arthritis: The importance of self-efficacy expectancies. Patient Education Counselling, 36, 57-64. http://dx.doi.org/10.1016/S0738-3991(98)00087-1

Bultman, D. C., \& Svarstad, B. L. (2000). Effects of physician communication style on client medication beliefs and adherence with antidepressant treatment. Patient Education and Counseling, 40, 173-185. http://dx.doi.org/10.1016/S0738-3991(99)00083-X

Burgoon, M., Parrott, R., Burgoon, J. K., Coker, R., Pfau, M., \& Birk, T. (1990). Patients' severity of illness, non-compliance, and locus of control, and physicians' compliance gaining messages. Health Communication, 2, 29-46. http://dx.doi.org/10.1207/s15327027hc0201_3

Burgoon, J. K., Pfau, M., Parrott, R., Birk, T., Coker, R., \& Burgoon, M. (1987). Relational communication, satisfaction, compliance-gaining strategies, and compliance in communication between physicians and patients. Communication Monographs, 54, 307-324. http://dx.doi.org/10.1080/03637758709390235

Cameron, C. (1996). Patient compliance: Recognition of factors involved and suggestions for promoting compliance with therapeutic regimens. Journal of Advanced Nursing, 24, 244-250. http://dx.doi.org/10.1046/j.1365-2648.1996.01993.x

Campbell, T. A., Auerbach, S. M., \& Kiesler, D. J. (2007). Relationship of interpersonal behaviors and health-related control appraisals to patient satisfaction and compliance in a university health center. 0 American College Health, 55, 333-340. http://dx.doi.org/10.3200/JACH.55.6.333-340

Carpenter, D. M., DeVellis, R. F., Fisher, E. B., DeVellis, B. M., Hogan, S. L., \& Jordan, J. M. (2010). The effect 
of conflicting medication information and physician support on medication adherence for chronically ill patients. Patient Education and Counseling, 81, 169-176. http://dx.doi.org/10.1016/j.pec.2009.11.006

Conrad, P. (1985). The meaning of medications: Another look at compliance. Social Science and Medicine, 20, 29-37. http://dx.doi.org/10.1016/0277-9536(85)90308-9

Cutrona, S. L., Choudhry, N. K., Stedman, M., Servi, A., Liberman, J. N., Brennan, T., ... Shrank, W. H. (2010). Physician effectiveness in interventions to improve cardiovascular medication adherence: A systematic review. Journal of General Internal Medicine, 25, 1090-1096. http://dx.doi.org/10.1007/s11606-010-1387-9

Cvengros, J. A., Christensen, A. J., Hillis, S. L., \& Rosenthal, G. E. (2007). Patient and physician attitudes in the health care context: Attitudinal symmetry predicts patient satisfaction and adherence. Annals of Behavioral Medicine, 33, 262-268. http://dx.doi.org/10.1007/BF02879908

De Geest, S., Von Renteln-Kruse, W. V., Steeman, E., Degraeve, S., \& Abraham, I. L. (1998). Compliance issues with the geriatric population. Nursing Clinics of North America, 33, 467-480.

Dilorio, C., McCarthy, F., Depadilla, L., Resnicow, K., Holstad, M. M., Yeager, K., ... Lundberg, B. (2009). Adherence to antiretroviral medication regimens: A test of a psychosocial model. Aids and Behavior, 13, 10-22. http://dx.doi.org/10.1007/s10461-007-9318-4

DiMatteo, M. R. (1994). Enhancing patient adherence to medical recommendations. Journal of the American Medical Association, 271, 79-83. http://dx.doi.org/10.1001/jama.271.1.79

DiMatteo, M. R. (2004a). Variations in patients' adherence to medical recommendations: A quantitative review of 50 years of research. Medical Care, 42, 200-209. http://dx.doi.org/10.1097/01.mlr.0000114908.90348.f9

DiMatteo, M. R. (2004b). Social support and patient adherence to medical treatment: A meta-analysis. Health Psychology, 23, 207-218. http://dx.doi.org/10.1037/0278-6133.23.2.207

DiMatteo, M. R., Haskard, K. B., \& Williams, S. L. (2007). Health beliefs, disease severity, and patient adherence: A meta-analysis. Medical Care, 45, 521-528. http://dx.doi.org/10.1097/MLR.0b013e318032937e

DiMatteo, M. R., Reiter, R. C., \& Gambone, J. C. (1994). Enhancing medication adherence through communication and informed collaborative choice. Health Communication, 6, 253-265. http://dx.doi.org/10.1207/s15327027hc0604_2

DiMatteo, M. R., Sherbourne, C. D., Hays, R. D., Ordway, L, Kravitz, R. L., McGlynn, E., ... Rogers, W. H. (1993). Physicians' characteristics influence patients' adherence to medical treatment: Results from the medical outcomes study. Health Psychology, 12, 93-102. http://dx.doi.org/10.1037/0278-6133.12.2.93

Donovan, J. L., \& Blake, D. R. (1992). Patient non-compliance: Deviance or reasoned decision making? Social Science and Medicine, 34, 507-513. http://dx.doi.org/10.1016/0277-9536(92)90206-6

Dunbar-Jacob, J. (1993). Contributions to patient adherence: Is it time to share the blame? Health Psychology, 12, 91-92. http://dx.doi.org/10.1037/0278-6133.12.2.91

Falvo, D., Woehlke, P., \& Deichmann, J. (1980). Relationship of physician behaviour to patient compliance. Patient Counseling and Health Education, 2, 185-188. http://dx.doi.org/10.1016/S0738-3991(80)80101-7

Fishbein, M. (1968). An investigation of relationships between beliefs about an object and the attitude towards that object. Human Relationships, 16, 233-240. http://dx.doi.org/10.1177/001872676301600302

Foster, J. M., Smith, L., Bosnic-Anticevich, S. Z., Usherwood, T., Sawyer, S. M., Rand, C. S., \& Reddel, H. K. (2011). Identifying patient-specific beliefs and behaviours for conversations about adherence in asthma. Internal Medicine Journal. Advance online publication.

Gellad, W. F., Grenard, J. L., \& Marcum, Z. A. (2011). A systematic review of barriers to medication adherence in elderly: Looking beyond cost and regimen complexity. The American Journal of Geriatric Pharmacotherapy, 9, 11-23. http://dx.doi.org/10.1016/j.amjopharm.2011.02.004

Haynes, R. B., McDonald, H. P., \& Garg, A. X. (2002). Helping patients follow prescribed treatment: Clinical applications. Journal of the American Medical Association, 288, 2868-2879. http://dx.doi.org/10.1001/jama.288.22.2880

Haynes, R. B., Taylor, D. W., Sackett, D. L., Gibson, E. S., Bernholz, C. D., \& Mukherjee, J. (1980). Can simple clinical measurements detect patient non-compliance? Hypertension, 2, 757-764.

Horne, R., \& Weinman, J. (1999). Patients' beliefs about prescribed medicines and their role in adherence to treatment in chronic physical illness. Journal of Psychosomatic Research, 47, 555-567. 
http://dx.doi.org/10.1016/S0022-3999(99)00057-4

Jerant, A., Chapman, B., Duberstein, P., Robbins, J., \& Franks, P. (2010). Personality and medication non-adherence among older adults enrolled in a six-year trial. British Journal of Health Psychology, 16, 151-169. http://dx.doi.org/10.1348/135910710X524219

Kaplan, R. M., \& Simon, H. J. (1990). Compliance in medical care: Reconsideration of self predications. Annals of Behavioral medicine, 12, 66-71. http://dx.doi.org/10.1207/s15324796abm1202_2

Karamanidou, C., Clatworthy, J., Weinman, J., \& Horne, R. (2008). A systematic review of the prevalence and determinants of nonadherence to phosphate binding medication in patients with end-stage renal disease. BMC Nephology, 9, 2. http://dx.doi.org/10.1186/1471-2369-9-2

Kennedy, J., \& Morgan, S. (2009). Cost-related prescription nonadherence in the United-States and Canada: A system-level comparison using the 2007 international health policy survey in seven countries. Clinical Therapeutics, 31, 213-219. http://dx.doi.org/10.1016/j.clinthera.2009.01.006

Kerse, N., Buetow, S., Mainous III, A. G., Young, G., Coster, G., \& Arroll, B. (2004). Physician-patient relationship and medication compliance: A primary care investigation. Annals of Family Medicine, 2, 455-461. http://dx.doi.org/10.1370/afm.139

Laurier, C., \& Lafortune, D. (2007). Les facteurs contribuant à l'observance d'une psychopharmacothérapie chez les adolescents hébergés en centres de réadaptation. Psychologie canadienne, 48, 211-220.

Lehane, E., \& McCarthy, G. (2007). Intentional and unintentional medication non-adherence: A comprehensive framework for clinical research and practice? A discussion paper. International Journal of Nursing Studies, 44, 1468-77. http://dx.doi.org/10.1016/j.ijnurstu.2006.07.010

Lehane, E., \& McCarthy, G. (2009). Medication non-adherence: Exploring the conceptual mire. International Journal of Nursing Practice, 15, 25-31. http://dx.doi.org/10.1111/j.1440-172X.2008.01722.x

Lerner, B. H. (1997). From careless consumptives to recalcitrant patients: The historical construction of non-compliance. Social Science and Medicine, 45, 1423-1431. http://dx.doi.org/10.1016/S0277-9536(97)00067-1

Li, H. Z., \& Browne, A. (2000). Defining mental health illness and accessing mental health services: Perspectives of Asian immigrants. Canadian Journal of Community Mental Health, 19, 143-159.

Li, H. Z., Desroches, N., Yum, O. K., Koehn, C., \& Deagle, G. (2007). Asymmetrical talk between physicians and patients: A quantitative discourse analysis. Canadian Journal of Communication, 32, 417-433.

Mann, D. M., Ponieman, D., Leventhal, H., \& Halm, E. A. (2009). Predictors of adherence to diabetes medications: The role of disease and medication beliefs. Journal of Behavioral Medicine, 32, 278-284. http://dx.doi.org/10.1007/s10865-009-9202-y

Miller, P., Wikoff, R., \& Hiatt, A. (1992). Fishbein's model of reasoned action and compliance behavior of hypertensive patients. Nursing Research, 41, 104-109. http://dx.doi.org/10.1097/00006199-199203000-00009

Molloy, G. J., Perkins-Porras, L., Bhattacharyya, M. R., Strike, P. C., \& Steptoe, A. (2008). Practical support predicts medication adherence and attendance at cardiac rehabilitation following acute coronary syndrome. Journal of Psychosomatic Research, 65, 581-586. http://dx.doi.org/10.1016/j.jpsychores.2008.07.002

Pahal, J. (2004). Resident-patient communication (Unpublished Master's Thesis). University of Northern British Columbia: Prince George, Canada.

Parsons, T. (1951). The social system. New York, NY: The Free Press of Glencoe.

Rosenstock, I. M. (1974). Historical origins of the health belief model. Health Education Monographs, 2, 228-235.

Rosenstock, I. M. (1988). Enhancing patient compliance with health recommendations. Journal of Pediatric Health Care, 2, 67-72. http://dx.doi.org/10.1016/0891-5245(88)90169-1

Ross, F. M. (1991). Patient compliance: Whose responsibility? Social Science and Medicine, 32, 89-94. http://dx.doi.org/10.1016/0277-9536(91)90132-V

Roter, D. L., Hall, J. A., Merisca, R., Nordstrom, B., Cretin, D., \& Svarstad, B. (1998). Effectiveness of interventions to improve patient compliance: A meta-analysis. Medical Care, 36, 1138-1161. http://dx.doi.org/10.1097/00005650-199808000-00004 
Roter, D. L., Stewart, M., Putnam, S. M., Lipkin, M., Stiles, W., \& Inui, T. S. (1997). Communication patterns of primary care physicians. Journal of the American Medical Association, 277, 350-356. http://dx.doi.org/10.1001/jama.277.4.350

Ryan, A. A. (1999). Medication compliance and older people: A review of the literature. International Journal of Nursing Studies, 36, 153-162. http://dx.doi.org/10.1016/S0020-7489(99)00003-6

Sackett, D. L., \& Snow, J. C. (1979). The magnitude of compliance and non-compliance. In Haynes, R. B., Taylor, D. W., \& Sackett, D. L. (Eds.), Compliance in health care (pp. 11-22). Baltimore, MD: John Hopkins University Press.

Schüz, B., Wurm, S., Ziegelmann, J. P., Warner, L. M., Tesch-Römer, C., \& Schwarzer, R. (2011). Changes in functional health, changes in medication beliefs, and medication adherence. Health Psychology, 20, 31-39.

Sherbourne, C. D., Hays, R. D., Ordway, L., DiMatteo, M. R., \& Kravitz, R. L. (1992). Antecedents of adherence to medical recommendations: Results from the Medical Outcomes Study. Journal of Behavioral Medicine, 15, 447-468. http://dx.doi.org/10.1007/BF00844941

Siegel, S. D., Turner, A. P., \& Haselkorn, J. D. (2008). Adherence to disease-modifying therapies in multiple sclerosis: Does caregiver social support matter? Rehabilitation Psychology, 53, 73-79. http://dx.doi.org/10.1037/0090-5550.53.1.73

Sleator, E. K. (1985). Measurement of compliance. Psychopharmacology Bulletin, 21, 1089-1093.

Stafford, L., Jackson, H. J., \& Berk, M. (2008). Illness beliefs about heart disease and adherence to secondary $\begin{array}{lllll}\text { prevention } & \text { regimens. } & \text { Psychosomatic } & \text { Medicine, } & 70,\end{array}$ http://dx.doi.org/10.1097/PSY.0b013e318187e22e

Stephens, M. A. P., Fekete, E. M., Franks, M. M., Rook, K. S., Druley, J. A., \& Greene, K. (2009). Spouses' use of pressure and persuasion to promote osteoarthritis patients' medical adherence after orthopedic surgery. Health Psychology, 28, 48-55. http://dx.doi.org/10.1037/a0012385

Stimson, G. V. (1974). Obeying doctors' orders: A view from the other side. Social Science and Medicine, 8 , 97-104. http://dx.doi.org/10.1016/0037-7856(74)90039-0

Trostle, J. A. (1988). Medical compliance as an ideology. Social Science and Medicine, 27, 1299-1308. http://dx.doi.org/10.1016/0277-9536(88)90194-3

Verde, M., \& Li, H. Z. (2003). Are native men and women accessing the health care facilities? Findings from a small native reserve. Canadian Journal of Native Studies, 23, 143-164.

\section{Note}

Note 1 . The previous four steps were also performed with the centered variables. 